\title{
Africanity and research: A case study in rural South Africa
}

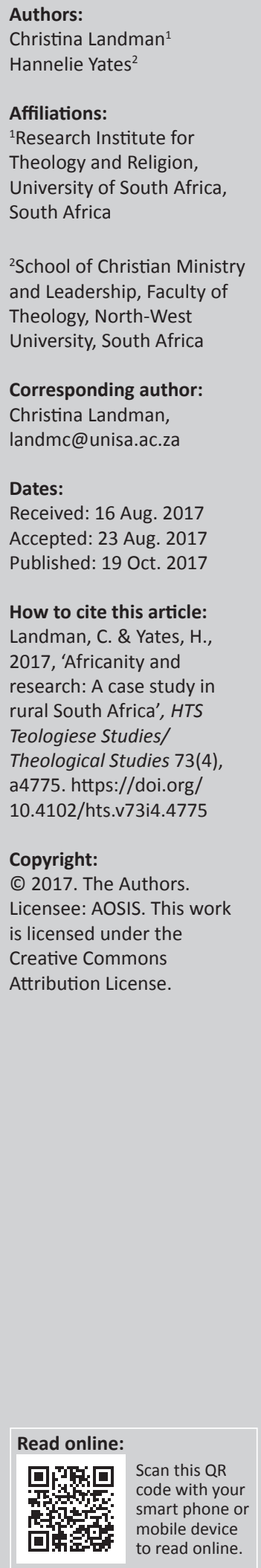

In the first part of this article, Africanity as a concept within research methodology is explored in the dialogical spaces between the binaries of racial identity and group identity, indigenous and traditional values, post-colonialism and post-racialism, blackness and African, as well as eliminativist and conservationalist. In the second part, the research carried out in two townships in the eMakhazeni Local Municipality in Mpumalanga, South Africa's most eastern province, is described in terms of parameters and process. The townships involved are Sakhelwe in Dullstroom-Emnotweni and Emthonjeni in Machadodorp-eNktokozweni. The research focuses on interviews with young people between the ages of 18 and 24 on the potential of faith-based organisations to assist them in moving from the 'margins' of society to positions of social cohesion. The third and main part of the article, is dedicated to lessons learnt and experience acquired when research is carried out in a rural area from an Africanity perspective. This entails, inter alia (1) to be sensitive towards power relations in research; (2) respecting indigenous values within group identities; (3) not predefining the youth, using indigenous (and not European) definitions of 'agency' and 'marginalisation'; (4) to engage in observation rather than interpretation; and (5) to decolonise the research process when regarding interpretation as an act of colonisation.

\section{Introduction: Aim and structure}

The aim of this article is to explore the concept of 'Africanity' as a methodological point of departure in research. The context is young people in rural communities and their expectations of faith-based organisations (FBOs). The research population consists of 46 young rural people between the ages of 18 and 24 years living in Dullstroom-Emnotweni and MachadodorpEmtonjeni on the Mpumalanga Highveld in the east of South Africa.

To accommodate this aim, the article is structured into three sub-sections. Firstly, 'Africanity' is defined as a methodological concept. Secondly, background information on the case study in Dullstroom-Emnotweni and Machadodorp-Emtonjeni is provided, as well as the parameters of the research process followed. The third and final part of the article, which is the most important and relevant to the topic at hand, deals with the lessons learnt while researching from an 'Africanity' point of view. The voices of the youth, presented in an unmediated way, are used to illustrate the research process and findings.

\section{Africanity defined as a methodological concept}

The concept 'Africanity' calls for a unique definition because it is popularly understood within a wide, and mostly generic, reference. The term 'Africanity' has been in academic usage for almost 5 decades and can be traced back to the book of Jacques Maquet entitled Africanity: The cultural unity of black Africa, published in 1972 by Indiana University Press; it takes a (white) look at Africanity as the 'state of being African or having African origins', reflecting on the aspects that bind African cultures together or distinguish them from one another.

Probably because of its 'white' origin, the term 'Africanity' was embraced by black scholars (both African and American) only at a later stage. During the 1980s, the term became synonymous with the work of the Islamic writer and intellectual Ali Mazrui (see Laremont \& Seghatolislami 2002). It is only during the past 20 years that black scholars have been using the term 'Africanity' frequently, and then mainly in a generic way to denote racial identity (Ya Azibo, Robinson \& Scott-Jones 1996:246) or cultural identity (Tshaka 2007:541).

The theologian, Rothney Tshaka (2007:541), is the most pronounced South African scholar on Africanity. He problematises the concept of 'Africanity' by referring, on the one hand, to the 
standpoint held by African scholars that the 'inclination to make everyone African was bemoaned'. Tshaka includes himself with those who think that 'an African is one who is holistically rooted in the cultural setting from which $\mathrm{s} /$ he originated', and that 'one cannot be converted to being an African'. On the other hand, he entertains the preference of those - like Thabo Mbeki - who locate the essence of Africanity 'not in race but in commitment to the ideals of this continent' (Tshaka 2007:542).

The authors of this article place 'Africanity' within the dialogical spaces between cultural nationalism and racial inclusion as (albeit partially) afforded by Tshaka. The authors' definition of Africanity is informed by the following presuppositions:

- Africanity does not primarily refer to racial identity, but to group identity, that is, to those who identify with their African origins, irrespective of race.

- Africanity deals not only with the socio-economic and political context of African people, but includes the indigenous values of African cultures that are not necessarily traditional. The distinction is made between indigenous as values that are inherently accepted by the group, and traditional values that were part of the group but from which they might have distanced them. Human rights, as an example, might be indigenous to a group while it might not have been traditionally acknowledged in quite the same way as in modern times.

- Africanity is regarded as post-colonial, but - regrettably so - not yet as post-racial (as argued in Smith et al., 2015 in their book Contesting post-racialism).

- Africanity is neither eliminativist (which argues that race is a social construct and can be eliminated) nor conservationalist (which argues that if race is eliminated, society will still not be equal); thus, the authors use the term to refer to race as still being a determinate force in society, albeit unfortunately so. Fluker (2015:39-40) quotes Richard Jones 'in thinking about race as a resilient, shifting, and revisable historical reality that is constantly adapting to new social situations'.

- Africanity is not equal to blackness, but refers to ways of being and thinking within African contexts.

The authors' definition of Africanity, therefore, reads as follows: 'Africanity refers to the values indigenous to a group which identifies with African ways of being and thinking'.

This definition has the following implications for Africanity when used as a methodological concept, noting that the methodology of Africanity is, to a great degree, compatible with the values of Narrative Inquiry (as described by Cladinin 2007):

- Amethodological sensitivity towards cultural sentiments is presupposed, and space is created for reaching out between researcher and interviewee in an autoethnographical way in which the life stories of both are blended into a story according to the values of the group's identity.
- The relationship between the interviewer and interviewee is one of equality, reciprocity and mutual respect, moving from the objective to the relational, a relation in which African contexts and voices matter.

- The 'research population' is not used as 'data fishponds' but preferably trained to become interviewers themselves in terms of capacity building and job creation.

- Words are considered as data, and every story is respected as having an integrity of its own. Experience is important, whether it can be proved as 'true' or not. Data given in stories are treated so as to enable the interviewee and not to dehumanise him or her.

- There is a movement away from what is considered normal, researchable and reportable by the Western academic society. Western notions such as the 'marginalisation' of the youth according to the Not in Education, Employment and Training (NEET) categories are sidelined in favour of the indigenous values of agency and assets.

- Values such as objectivity, generalisation and positivistic validity are rejected in favour of a joint journey of selfgrowth between interviewer and interviewee in which both become reflexive of their lives.

\section{Rural eMakhazeni: Parameters and process of a case study Choosing research sites ${ }^{2}$}

Because the research focuses on Africanity in rural contexts, the two 'townships' of Sakhelwe (in Dullstroom-Emnotweni) and Emthonjeni (in Mashadodorp-eNtokozweni) were chosen as typical of the geographical, educational and social challenges faced by rural youth in South Africa today. The authors gained access to this research population with Landman being the minister of the Word in the Uniting Reformed Church in Southern Africa in the township of Sakhelwe, and konsolent [substitute minister] in the township of Emthonjeni.

\section{Locality, educational facilities and employment opportunities}

In terms of locality, the research sites are at least $50 \mathrm{~km}$ removed from any sizable town (Lydenburg, Belfast and Middelburg); they, therefore, lack basic resources in terms of food security, medical care, educational facilities and technology. Only half of the 8000 inhabitants of Sakhelwe and the 15000 people living in Emthonjeni have access to running water, while $70.0 \%$ have electricity. There is an estimated $89.0 \%$ unemployment and $47.2 \%$ HIV infection in the townships (Census 2011, Municipal Report, Mpumalanga 2012, www.statssa.gov.za).

1.The designation 'data fishponds' is used to acknowledge - with irony - the fact that the white town of Dullstroom is known for its fly-fishing from which the black population gains very little.

2.Between 2013 and 2016 the authors participated in a research project with Nordic and South African universities on the relationship between 'marginalised' youth and FBOs. The project was entitled "Youth on the Margins" (YOMA). The authors were responsible for one of the six case studies, which was the only one conducted in a responsible for one of the six case studies, which was the only one conducted in a
rural area, that is, in the eMakhazeni Local Municipality on the Mpumalanga Highveld in eastern South Africa. 
In Sakhelwe (in Dullstroom-Emnotweni), the only jobs available to the youth are in the hospitality industry, that is, to be employed as waiters and cleaners in the 27 restaurants in white Dullstroom's main street. Young members of the Unemployment Peoples' Organisation (UPOC) in Sakhelwe related their frustration when trying to create jobs for themselves amid white structures and values (Landman 2015:5).

Mphilonhle Primary School and Siyifunile Secondary School provide basic education in Sakhelwe, however, within an absence of computer and laboratory facilities, and smart phones. In Sakhelwe, $20.4 \%$ of people over the age of 20 had never been exposed to schooling, while about $30 \%$ of children of school going age (5-24 years) do not attend school at present (Census 2011, Municipal Report, Mpumalanga 2012, www.statssa.gov.za).

The same socio-economic crisis situation exists in Machadodorp's township. Statistics on HIV infection have not been released by the clinic in Emthonjeni (in Machadodorp-eNtokozweni). Unemployment in this township is exceptionally high because of the closing of the Assman Chrome factory in 2015, and the scaling down of the Nkomati Mine (Integrated Development Plan [IDP] 2016:103). Emthonjeni is double the size of Sakhelwe in terms of population and has five times more 'shacks' in informal settlements. Both townships suffer from a huge shortage of permanent housing. 'eMakhazeni has a backlog of 3200 housing applications as per the municipal housing database' (IDP 2016:104).

Emthonjeni accommodates pre-school and after-school facilities originally built by Assmang Chrome Factory as part of their social responsibility as a business. Dumezizweni Primary School and Sikhulile Secondary School provide primary and secondary education, while $10.1 \%$ of people over 20 have never received schooling. In the whole of eNtokozweni, $8.9 \%$ of the people have received tertiary education, which is high in comparison with the $1.4 \%$ of Sakhelwe (Census 2011, Municipal Report, Mpumalanga 2012, www.statssa.gov.za).

In both Sakhelwe and Emthonjeni, the local businesses mainly spaza shops ${ }^{3}$ - do not belong to the local people but to shop owners coming from Pakistan, Zimbabwe and Mozambique.

\section{The youth situation}

The Integrated Development Plan of eMakhazeni (2016:6869) lists the following as challenges experienced by the Municipality in obtaining their goal of 'creating an enabling environment that will alleviate poverty and promote economic growth and development' vis-à-vis the youth: lack of career guidance and skills shortage; youth delinquency; under-parenting; increasing number of child-headed families; moral decay; teenage pregnancy at school; substance 3.Shops in informal buildings selling basic groceries. and drug abuse; and the high rate of unemployment because of a lack of job opportunities for the youth.

The strategies envisaged by the IDP of the Municipality are aimed at capacitating the youth with education and practical skills, combatting substance and drug abuse, and conscientising the youth about HIV and AIDS. The aim is to produce skilled and employable youth, who lead a healthier lifestyle with reduced pregnancies, substance and drug abuse and HIV and AIDS prevalence.

In 2016, half a million rand was budgeted by the Municipality to achieve these aims through sports development, arts and culture development, drug and substance abuse awareness campaigns, health promotion awareness campaigns, teenage pregnancy dialogue, career guidance, capacity building workshops and entrepreneurship development programmes.

However, the only visible outcome of these strategies is the youth centres in the townships, that is, Sakhisizwe Youth Centre in Sakhelwe and the Vukukhanye Youth Centre in Emthonjeni. These youth centres consist only of three to five computers each. In the youth centre in Sakhelwe, it was pointed out that the data provided for internet services were extremely limited and that the youth do not visit the centres because their computer skills are limited (there are no computers at school) and they do not want to make fools of themselves at the centre.

Recreational facilities are restricted to informal soccer fields, and the youth find their 'recreation' at the numerous shebeens (or drinking places). There is a small library in white Dullstroom that is limited to Afrikaans and English books.

In terms of Africanity research, two remarks are to be made about this situation. Firstly, according to the IDP the youth between the ages of 15 and 24 constitute more than $25 \%$ of the inhabitants of eMakhazeni. Although they are the largest of all age groups in eMakahazeni, the youth nevertheless remain voiceless and with their agency unrecognised. The second remark is that the IDP of the Municipality does not, in any of its planning, strategies or implementation plans involve the FBOs in any way, thereby ignoring the indigenous preferences of the society.

\section{Religious context}

In Sakhelwe, there are three main churches, two of them congregations of national churches and one an independent church. These three are, firstly, the Uniting Reformed Church in Southern Africa, previously known as the Dutch Reformed Church in Africa, and an indigenous mainline church. Secondly, there is the Zion Christian Church (ZCC), the largest African Independent Church in South Africa. Thirdly, one finds the Elohim Bible Church which is a popular independent church. The St John's Apostolic Faith Mission appeared recently and modestly on the scene, as well as other independent churches from inter alia KwaZulu-Natal. There is a mosque situated on the border between white Dullstroom 
and Sakhelwe with an onsite Imam. Neither the Imam nor the five sangomas (traditional healers) in Sakhelwe afforded the researchers any interviews.

Moving to Machadodorp (-eNokhozeni) and its township Emtonjeni, one finds a much greater variety of churches. In the previously white town of Machadodorp too an apparently affluent mosque is found, but according to Pastor T (Resource person 2) there are very few Muslims. The Christian churches in Emthonjeni include a variety of names and those significant to the youth were revealed by the youth themselves during a group interview on 08 April 2016. They are the Uniting Reformed Church in Southern Africa, the Roman Catholic Church, the Church of the Nazarene, the Holiness Union Church, Seventh Day Adventist Church, True Worshippers of God Church, African Methodist Episcopal Church, the ZCC and the Kingdom Life Church. Pastor T (Resource Person 2) adds the names of the Faith Mission Mighty Power, In Presence of God, Solid Rock, and the Holy Bible Focus. Most of these independent churches do not have building structures. However, there is a church building for the Methodist Church in the previously white town 'for those who come from the outside', that is, white people, according to Pastor T.

\section{Method}

\section{Mapping}

The mapping of resources was carried out in two phases. Firstly, the researchers orientated themselves vis-à-vis the physical context of Sakhelwe and Emthonjeni by driving up and down, from street to street, to map the assets of these communities. This was performed with gatekeeper Paulus Mnisi, who was the leader elder at the Uniting Reformed Church in Southern Africa in Sakhelwe, but also knew both physical contexts intimately. ${ }^{4}$ This first phase of mapping confirmed the scarcity of educational and recreational resources for the young, as well as health facilities, described in the previous paragraphs.

Secondly, a CAMP workshop, that is, a Community Asset Mapping Programme workshop, was held in Sakhelwe on 15 to 18 July 2014 and hosted by the Department of Geography from the University of South Africa and the Greater Rustenburg Community Foundation. ${ }^{5}$ It was attended by 27 young people from Sakhelwe and Emtonjeni.

In terms of the methodological insights of Africanity research that regard the youth as equal research partners, the following results of the CAMP mapping process are significant: (1) The youth do not see the church as an asset to society; they concur that FBOs are not acknowledged by national of local government as role players in youth development. (2) The

4.Paulus Mnisi died on 07 June 2017

5.The facilitators and assistants of the CAMP workshop were M. Nicolau (Geography, Unisa), C. Delport (GRCF), B. Mmokele (GRCF), H. Steenkamp (Geography, Unisa), R Pienaar (Geography, Unisa), B. Khanye (Geography, Unisa), S. TShabalala (Geography, Unisa), K. Letshaba (Tirisano Centre, Unisa) and H. Lesele (Tirisano Centre, Unisa). A Unisa), K. Letshaba (Tirisano Centre, Unisa) and H. Lesele (Tirisano Centre, Unisa). A
copy of this report can be obtained from Dr M.D. Nicolau, the CoD of the Department copy of this report can be obtained from Dr M.D. Nicolau, the CoD of
of Geography at Unisa, 0027114712084 or nicolmd@unisa.ac.za. youth note that churches themselves are in conflict with one another and, therefore, not trustworthy partners in social cohesion. (3) The eMakhazeni Municipality is not seen as a partner but a problem in the development of the youth. The youth feel that their agency is not recognised, because it has been stolen from them by the Municipality which took decisions on their behalf without consulting them. (4) The youth see turning back to culture and tradition as a source of agency, and consequently they experience conflict between their religious and cultural identities.

\section{Conducting interviews}

The following sets of interviews inform this research:

Subset 01: Focus Group 1, Sakhelwe (DullstroomEmnotweni). Four young people between the ages of 18 and 24 were interviewed at URCSA Mission House on 08 December 2015: two women and two men, two Ndebele and two Swazi, three from URCSA and one for the Kingdom Life Connections Worship Centre.

Subset 02: Focus Group 2, Sakhelwe (DullstroomEmnotweni). Four young people between the ages of 18 and 24 were interviewed at URCSA Mission House on 08 December 2015: four men, none of them from URCSA.

Subset 03: Focus Group 3, Sakhelwe (DullstroomEmnotweni). Five young people between the ages of 18 and 24 were interviewed at URCSA Mission House on 08 December 2015: three women and two men, one from URCSA and the others with no definite church affiliation.

Subset 04: Individual Interview 1. Nene (pseudonym), an 18-year-old Swazi male from URCSA, was interviewed at the URCSA Mission House on 08 December 2015.

Subset 05: Individual Interview 2. Slater (pseudonym), a 24-year-old woman not belonging to a church, was interviewed at the URCSA Mission House on 08 December 2015.

Subset 06: Individual Interview 3. Gift (pseudonym), a 24-year-old woman from the Elohim Bible Church was interviewed at the URCSA Mission House on 08 December 2015.

Subset 07: Group Interview, Emthonjeni (MachadodorpeNtokozweni). A group of 30 young people between the ages of 18 and 24 were interviewed at the Vukukhanye Youth Centre in Emthonjeni on 08 April 2016.

Subset 08: Resource Person 1: Pastor C from an independent church in Sakhelwe. He was interviewed in the eMakhazeni Local Municipality offices in Belfast on 04 March 2016.

Subset 09: Resource Person 2: Pastor T from an independent church in Emthonjeni. He was interviewed in his house in Machadodorp on 08 April 2016. 
Subset 10: Interviews were held with 13 resource people, including social and ancillary social workers at Machadodorp, the Youth Manager of eMakhazeni, an Evangelist of the Dutch Reformed Church, two officers from Dullstroom Police Station, one involved white man from Belfast and two involved white women individuals from Dullstroom. Church leaders were approached for interviews but were either not available or not eager to be interviewed.

In summary, 46 young people (18-24 years of age) and 15 resource people were interviewed, of whom half were women.

\section{Narrating the interviews}

The interviews were free-flowing; however, they focused on three questions, reflecting with the youth on (1) the challenges and (the lack of) opportunities in their daily lives, (2) their relationship with FBOs and (3) their expectations of what they can gain from their engagement with FBOs. These interviews, with their permission, were recorded and transcribed.

In terms of Africanity research, the interviews were not analysed in terms of covert and overt agendas, but are presented in publication in an unmediated way. That is, they are simply narrated according to the themes that emerged from the words of the youth themselves. These themes are: (1) no hope because of a lack of education and employment opportunities; (2) no respect from the Municipality, the churches, the schools and society; (3) no escape from drugs and abusive sex; and (4) no role models.

\section{Lessons learnt from Africanity research \\ Sensitising the self and 'the other' towards power relations}

One of the most powerful lessons learnt from this research in terms of Africanity values was the equalisation of power relations between 'interviewer' and 'interviewee(s)'.

Firstly, the researchers had to clarify for themselves their position vis-à-vis post-racialism and recognised their position as white researchers in a situation which was not yet postracial, but one in which they could deal with their postcolonial presuppositions. The researchers, furthermore, had to remain sensitive towards the fact that they, in the minds of the youth, not only represented 'the church' but indeed the 'missionary church'.

Secondly, the researchers - in partnership with the research participants - learnt to take responsibility for the voicelessness of those interviewed who often declared that 'We are not used to speaking our mind'.

Thirdly, the researchers had to acknowledge the influence of language on the research environment and results. The research participants had to express themselves in 'unnatural language', namely English in which the researchers were more fluent. On the power of language in research Ndimande (2012) says:

My method to incorporate Indigenous languages in this research instead of simply using English was, among other reasons to affirm and reinforce the importance of Indigenous languages in research connected to Indigenous communities. (p. 217)

Fourthly, the researchers were forced to obtain skills and create opportunities to convey this methodological value of equality to the research participants. This was performed in the following ways:

- The respect due between interviewers and research participants was openly pronounced.

- Research participants were invited to voice a call for respect.

- Ways were discussed between interviewers and research participants to undermine labels that were attached to the youth, that is, of being lazy, uncontrollable and immoral. The youth were invited to rescope themselves as role players and agents and to restore their human dignity in a society in which they were stigmatised.

- The researchers conveyed to the research participants their recognition of the special challenges of the youth in rural areas.

- The researchers strongly brought under the attention of the youth their willingness and eagerness to learn from them. This was necessary because of the researchers coming from a university context which might have threatened youth that considered themselves to be lacking opportunities for education.

Within this approach which allowed the youth to express themselves freely on the limitations of the FBOs, the youth voiced themselves on the first theme which they have identified, that is whether they regarded the FBOs as spaces of hope vis-à-vis the hopelessness of their present situation.

Some of the young voices expressed their concern that the churches did not know where they were going with the youth:

'Do the churches know that they are supposed to help us or do they have any information of where to go so that they can help us? Because we do go to them and ask for something and then they are just praying for us and then tells us to pray that's all.' (Group Interview, Emthonjeni)

Other voices pointed specifically to the irrelevance of the church as a place that would not provide you with bursaries, except for priesthood, and had no real programmes for the youth that addressed real life issues.

A majority of the voices of the youth nevertheless acknowledge the hope offered by FBOs with regards to moral improvement and direction, divine power towards changing lives, healing, identity, providing a space for safety and calmness, forgiveness and love: 
'Going to church offers us hope because we will learn about how God do the impossible. We look at people who yesterday were drunks on the street, not knowing what to do with their lives, but they did come to church and look their lives improved.' (Focus Group 3, Sakhelwe)

\section{Respecting indigenous values within group identities}

The second lesson learnt during this research was for all participants to respect the indigenous values of relevant group identities. Not only did the 'research population' consist of a variety of African cultures, the researchers also had to obtain skills to move from an outsider position to that of insider.

Respecting indigenous values as outsiders moving towards the inside, methodologically entailed the following:

- The researchers had to grow respectfully with young people of different ethnic groups sharing indigenous values across and beyond ethnic and generational divides. Ndimande explains how difficult it is even for a 'cultural insider' to move from an outside position towards the research participants while gaining their respect:

Engaging in a decolonizing approach also means facing the contradictions and complex notions of the 'insider' /'outsider' binaries. Even in a situation in which a researcher such as myself is considered simultaneously an 'insider' /'outsider', communities may not readily 'open up' because of several differences, including differences in structural positions ... (2012:221)

- The researchers had to negotiate with the research participants what 'respect' in a research context meant. Ndimande (2012:221) points to the following as research questions that earn respect and which the researchers should confront themselves with: 'Did you bring food to the interview? Were you patient with the interview participants? Were the questions respectful of the interview participants?' In our case, the research participants indeed expressed a preference for receiving food and money. However, the sponsors did not allow for interview participants to be paid. We have budgeted for food parcels and to train research participants as interviewers, but eventually time prevented us from doing this. The researchers asked themselves whether the practice of not paying participants might be Western and ultimately shows disrespect for the stories and time of the interview participants. The researchers are, furthermore, convinced that the paying of interview participants, as well as the handling of the informed consent form, should be done by an independent person.

- The researchers learnt to accommodate the interview participants during focus group interviews walk in and out of an interview without announcing their temporary department or asking permission. This was seen as an indigenous practice and part of the climate for dialogue created by the youth themselves.

- The researchers did not regard the youth as a homogenous group, neither did they expect mono-identities from individuals. The researchers endeavoured to embrace the diversity and diverse values of interview participants, acknowledging that traditional values have shifted in unique ways to indigenous values. The researchers negotiated inclusion by the group based on the terms of the group identity:

An Indigenous researcher needs to represent more than just the color of her or his skin. She or he needs to understand her or his multiple identities, including that of 'insider'/'outsider' as determined by Indigenous communities. Furthermore, a decolonizing approach requires us to navigate these complexities and nuances with serious caution to minimize or prevent barriers that can come in the way of research with the marginalized groups. (Ndimande 2012:221)

- However, acknowledging that cultures, languages, generations and contexts can be barriers in research, the researchers presupposed that the stories of interviewers and research participants could be respectfully blended when there was an awareness of underlying assumptions, motivations and values. Respecting one another played an important role in this process.

- The researchers had to acknowledge that research within rural dynamics offered special challenges, although they never experienced any 'disrespect' from interview participants, which might be a characteristic of rural group values. Acknowledging that the voices of the youth were in some sense compromised by the status of the researchers, it can nevertheless be reported that the youth freely expressed their disappointment with the divisions between churches and the fact that church leaders do not work together. This fact infringed on their respect for the churches. However, appreciation was voiced for individual church leaders that are not judgmental and willing to 'dirty their hands' with the young of the church.

Within this ambivalence as to the role of the church in their lives, the young people expected from the church to teach people to respect one another. This was a clear expectation from the youth and a rather solid conviction that the church was the appropriate agent for teaching respect:

'According to my opinion, in church they teach you how to treat others with manners or with respect. You must have respect for others so that you can get the respect back.' (Focus Group 2, Sakhelwe)

'If you go to church maybe you will get some respect or you must respect one another ...' (Focus Group 3, Sakhelwe)

'Those who go to church, they do respect. Yes and then they know the name of God. Those who do not go to church, they do not respect one another.' (Focus Group 2, Sakhelwe)

'The church teaches me how to respect myself and respect others and people's feelings.' (Group Interview, Emthonjeni)

Finally, some of the youth testified boldly to their human dignity being acknowledged and enhanced by the church:

'If I want something or did something bad, I can tell my pastor that I need some prayers so that he can make me feel like a human being ... The church can encourage people not to sleep with other people at a young age, looking for some disease such 
as HIV. The church should tell them that, wherever they go, they are not alone. Jesus is with them and won't let them do stupid things.' (Gift, Individual Interview 3)

The researchers noted that the main feature that marginalises the youth from social inclusion, is the fact that they did not feel respected by the few formal institutions that were present in their rural context, such as schools, the municipality and even their (mostly absent) parents. They felt that they were not listened to or consulted on their daily experiences, needs or future. They expressed themselves in this regard as follows:

'Our parents reject us; the teachers are beating us; we are two Grade 8 classes, one with 64 and the other with 74 learners. We are treated with no respect.' (Slater, Individual Interview 2)

'We are not used to voice our own opinions. Nobody seems to be interested in what we have to say. They take decisions on our behalf for what is good for us.' (Group interview, Emthonjeni)

'Without respect, nothing is helping you. It does not help if you are given things but you are not respected.' (Focus Group 3, Sakhelwe)

However, the youth reflected on having to show respect to others as well as to themselves:

'You must not disrespect another person's culture and the way he is doing things.' (Focus Group 3, Sakhelwe)

'They should respect what is in their hearts and not give in to peer pressure.' (Focus Group 3, Sakhelwe)

\section{Inviting self-constructions from the youth}

The third lesson learnt here in terms of Africanity research concerns the parameters of the invitation to the youth to construct themselves, firstly as research participants, secondly as inhabitants of a rural township and thirdly vis-àvis the church.

While asking ourselves whether we have asked the right research questions to empower the youth to construct themselves, the researchers came to the following three methodological insights:

- The researchers came to the research process with predestined constructions of the youth as belonging to the NEET category, as marginalised, and in need of skills. These Western, outsider and academic preconceptions had to be - and were to a lesser extent - deconstructed and new identities co-constructed with the youth as agents and in search of skills that were not imposed on them. Agency was seen by the youth as participation in the decision-making processes of inter alia local government, as well as in the processes of the research conducted. Agency was not seen as an individual trait but as a value within group identity. The fact that the interview schedule was - albeit partly - given to the youth and not negotiated fully, is seen by the researchers as a serious flaw in the research process.

- Secondly, the youth was to a certain extent enabled by the interview schedule to construct themselves within the hopes and hopelessness of their living conditions in a rural township. They described life as boring with major temptations from liquor, drugs and sex. The researchers were through their questioning, not fully able to turn this discourse of hopelessness into self-constructions away from victimhood towards control and dreaming. A lack of role models contributed to this largely negative self-construction by the youth. An exception to this was Nene who said:

'I have big dreams about my life ... my brother and my sister they are role models to me, that is why I want to see myself at University studying BCom ... I will not be in any tavern ... I will stay here in Dullstroom ... my dad never finished school, so he says to us to have great dreams and you must know what you deposit on your mind today is what you will draw tomorrow...' (individual interview 1)

This exception left the researchers with the unresolved methodological question whether it was good that we encouraged them to construct one another. Did our questions indeed enabled them to dream and to envisage a future, because they were stylised from the beginning as victims of NEET and marginalisation? 'I want to live a normal life', one of the participants said. Did our schedule allow us to investigate what 'normal' meant to them in a rural township?

- Thirdly, the youth constructed themselves vis-à-vis their relationship to the FBOs as one in which the FBOs provide them exclusively with spiritual support. The researchers were not able to co-construct with them a new view of FBOs other than only for spiritual guidance. Coconstructing a new relationship between youth and FBOs in terms of training, education and employment. The question remains unresolved whether it is the task of research to deconstruct minds captivated in victimhood although these researchers acknowledge the enabling task of research. In terms of Africanity research this will not be called 'development' but rather 'co-constructing enabling environments from existing assets and resources'.

The researchers observed that there was a clear expectation from the youth interviewed that the church should focus and improve on its moral training. This is in accordance with the findings of CAMP that the youth want to return to the basic principles of religion and culture to protect them from HIV infection, unwanted pregnancies and substance control:

'The church helps me to do the right things and not the wrong things' (Focus Group 3, Sakhelwe)

'When I think about those bad things (drugs and sex), then my inner voice says "no way am I going to do that". The church teaches you this thing, so your inner voice will protect you when it comes to these things.' (Focus Group 3, Sakhelwe)

'The church is very useful in terms of keeping the youth from dangerous stuff like drinking alcohol and being involved in drugs.' (Group interview, Emthonjeni)

\section{Observing instead of interpreting}

The main methodological lesson learnt during this research was for the researchers to compassionately observe and not to interpret. In terms of Africanity, the motto of the research process became 'interpreting is colonising'. 
This insight presents itself in at least four forms:

- Firstly, stories are accepted as data. This is in line with the 'Africanisation of knowledge' (see Msila 2014:431) that honour African experiences as communicated through stories.

- Secondly, the researchers entered into an observing process that did not point towards detachment, but towards compassionate learning.

- Thirdly, the researchers learnt that knowledge is to be obtained, and stories invited, not through probing and fishing but by asking relative influence questions. It has already been acknowledged that the questions were not negotiated with the interview participants beforehand. It, therefore, became even more important to engage in the exchange of knowledge respectfully.

- Fourthly, and most importantly, the knowledge obtained through stories was not interpreted. Interpretation was seen as colonisation. The voices of the interview participants were prepared for publication in an unmediated way, that is without asking for the truth and without analysing for hidden agendas. The researchers only looked for themes ${ }^{6}$ coming from the interview participants themselves, blending the life stories of the interviewers with that of the research participants. The researchers acknowledged that experience was methodologically of the utmost importance and shunned away even from 'clean observing' in favour of the sharing of experiences.

The theme of 'no escape from drugs and abusive sex', for instance, rendered the following results which, according to the methodological insights explained, are given here unmediated.

A circle of the youth described themselves as engaging in damaging behaviour because of an experience of rejection by their parents, while their parents claim to reject them because of this behaviour, as is expressed by Slater:

'Parents reject the children because they do not take life seriously. They don't look at their books. They just go to the taverns so they failed at the end of the year.' (Individual Interview 2)

With no jobs, educational opportunities or healthy role models available, the youth engage with what is available, that being drugs, alcohol and sex. The youth themselves expressed their dissatisfaction with substance and body abuse as the only securities available to them to shape their future. They do that as follows:

'Most of the youth are ignorant. They do not know what they want. They do not see the future. But if you can say there is a new shebeen, they will run and see!' (Focus Group 1, Sakhelwe)

'Even though you can come today, it's Monday, just pass the tavern and you will see that they are all there. The parents give them money to go and buy food while they work, then they take

6.These themes as previously indicated are: (1) no hope because of a lack of education and employment opportunities; (2) no respect from the Municipality, the churches, and employment opportunities; (2) no respect from the Municipality, the churches,
the schools and society; (3) no escape from drugs and abusive sex; and (4) no role the schools
models. out marog (spinach) to eat and go to the tavern and use the money there.' (Nene, Individual Interview 1)

The youth are conscious of the consequences of leading a life dominated by substance and body abuse:

'Dagga and those things are not good for the community because you end up stealing at home and then killing other people for their money.' (Focus Group 3, Sakhelwe)

'To be a young person who lives in Sakhelwe is not good if you are not working because you will end up doing dirty things like stealing or using drugs.' (Slater, Individual Interview 2)

The same criticism against themselves and the systems, which have failed them, are expressed on teenage pregnancy:

'it is like insurance instead of going to school ... as if having a baby will fix the problems they have.' (Focus Group 3, Sakhelwe)

'You are having a baby, you are part of the social grant. Maybe they think that money will help in the house, but it is still wrong to have a baby at a young age ... it is a wrong decision to make in life ... you are not able to feed the house and the baby with the grant money.' (Focus Group 3, Sakhelwe)

'Many girls in Dullstroom like money; they are in bad shape and they do not have a salary of their own. They depend on a man's salary. That is why you get one man having four girlfriends ... And that is why HIV is so high ... I want an educated girlfriend. She must be financially independent. If possible I want to marry a white girl.' (Nene, Individual Interview 1)

\section{Decolonising the research process: Conclusion}

This last paragraph serves as a conclusion to the lessons learnt and applied during research performed on the relationship between the youth and FBOs in two townships of eMakhazeni. The lessons learnt refer to the decolonising of research within the methodological insights of Africanity. Reference will also be made to the lessons learnt that could not be applied because of the initial non-African point of departure towards the research that was conducted in collaboration with European universities. Finally, further methodological challenges that need to be addressed will be mentioned.

Starting, then, with a summary of the lessons learnt:

- The equalising of the relationship between researchers and interview participants was one of the lessons learnt from the indigenous values of democratic Africa. Africanity as exploring the dialogical spaces between racism and an inclusive African group identity, allowed the researchers to participate in the research as negotiated insiders.

- 'Respect' as methodological praxis pertaining to all participants during research was honoured as an indigenous and negotiated African value. Dealing with the voices of the youth on their need for respect was a second lesson learnt during this research.

- The co-construction of both the identities of the interviewers and the interview participants was a skill and a lesson duly acquired and learnt by all during the research process, and the third lesson learnt. 
- The fourth skill learnt by the researchers during the said research was to undermine the colonising of the mind of the interview participants through interpretation. Apart from learning, not to look for facts that suit our hypothesis and using research methods that centralise the topic and not the interview participants, no interpretation as an analysis of hidden agendas was done. The voices of the youth were prepared for publication unmediatedly. The researchers eventually viewed interpretation as an act of colonisation and accepted that when stories are marginalised, identities remain colonised. The world view of the researchers was suspended to make place for the indigenous values within the group identity.

Many more lessons should be learnt from Africanity research:

- The researchers need to co-construct with interview participants the parameters of creating an enabling environment in which victimhood is deconstructed, and where hope is embodied in agency and actual possibilities. This is not to be called by the outsider term 'development'.

- More capacity building is to be done based on the needs voiced by participatory youth.

- Researchers and interview participants need to share the responsibility of 'freezing the walking voice' of those interviewed. A process of those interviewed taking ownership of their published voices need to be negotiated within the research values of Africanity.

- The researchers have acknowledged different ways of knowing and have given preference to acquiring knowledge through experience and storytelling. They have undermined positivistic academic values such as normality and objectivity. Much more need to be done to negotiate African ways of knowing.

- Religion researchers need to workshop with interview participants the question 'Are the FBOs colonisers?' in order to accommodate the FBOs within group identities that fall within the dialogical spaces between postcolonialism and post-racialism.

- Researchers and the interview participants need to negotiate the identities of FBOs within post-colonialism and post-racialism in order to address the question why local and national government do not regard the FBOs as agents for social change and social cohesion.

- Researchers need to retrieve the specific identities of religious agents in rural communities. Moving away from what is considered normal by developed academic society - not using them as objects of research, as datafishponds.
In conclusion, Africanity research does not mean normalising research in African contexts but decolonising the norms of traditional research to open spaces for indigenous voices to move from the margins to the centre.

\section{Acknowledgements Competing interests}

The authors declare that they have no financial or personal relationships which may have inappropriately influenced them in writing this article.

\section{Authors' contributions}

C.L. and H.Y. contributed equally to the gathering and analysis of the research data, as well as the compiling of findings in article format.

\section{References}

Census 2011 Municipal Report, Mpumalanga, 2012, Statistics South Africa, Pretoria, viewed 03 December 2016, from www.statssa.gov.za

Cladinin D.J. (ed.), 2007, Handbook of narrative inquiry: Mapping and methodology, Sage, Thousand Oaks, London, New Delhi.

Fluker, W.E., 2015, 'Shape-shifting: Cultural hauntings, contested post-racialism, and black theological imagination', in R.D. Smith et al. (eds.), Contesting post-racialism: Conflicted churches in the United States and South Africa, pp. 37-62, The University Press of Mississippi, Jackson, MS.

IDP eMakhazeni, 2016, Reviewed Integrated Development Plan, Final, viewed 02 December 2016, from http://www.emakhazeni.gov.za/IDP_EMAKHAZENI_LM_ 2016-17.pdf

Landman, C., 2015, 'Youth on the margins as agents of change? The call for the opening of mines in Dullstroom-Emnotweni based on the Freedom Charter (1955)', Studia Historiae Ecclesiasticae 41(1), 1-15. https://doi.org/10.17159/ 2412-4265/2015/v41n1a11

Laremont, R.R. \& Seghatolislami, T.L., 2002, Africanity redefined: Collected essays of Ali A Mazrui, Africa World Press, Trenton, NJ. Three more volumes followed.

Maquet, J.J.P., 1972, Africanity: The cultural unity of black Africa, Oxford University Press, Oxford, USA.

Msila, V., 2014, 'Fostering Africanisation: A lesson of identity formation among youth'. Mediterranean Journal of Social Sciences 5(8), 431-440.

Ndimande, B.S., 2012, 'Decolonising research in Postapartheid South Africa: Politics of methodology', Qualitative Inquiry 18(3), 215-226. https://doi.org/10.1177/ 1077800411431557

Sakhelwe CAMP Report, Department of Geography from the University of South Africa and the Greater Rustenburg Community Foundation. Co-authors $M$. Nicolau (Geography, Unisa), C. Delport (GRCF), B. Mmokele (GRCF), H. Steenkamp Nicolau (Geography, Unisa), C. Delport (GRCF), B. Mmokele (GRCF), H. Steenkamp
(Geography, Unisa), R. Pienaar (Geography, Unisa), B. Khanye (Geography, Unisa), S. TShabalala (Geography, Unisa), K. Letshaba (Tirisano Centre, Unisa), H. Lesele (Tirisano Centre, Unisa).

Smith, R.D., Ackah, W., Reddie, A.G. \& Tshaka, R.S., (eds.), 2015, Contesting postracialism: Conflicted churches in the United States and South Africa, The University Press of Mississippi, Jackson, MS.

Tshaka, R.S., 2007, 'African, you are on your own! The need for African Reformed Christians to seriously engage their Africanity in their Reformed Theological reflections', Scriptura 96, 533-548.

Ya Azibo, D.A.., Robinson, T. \& Scott-Jones, G., 2011, 'Psychological Africanity as racial identity: Validation of African American Multidimensional Racial Identity Scale, Black Personality Questionnaire, and Cultural Misorientation Scale', Western Journal of Black Studies 35(4), 246-267. 